\title{
Elevated airborne beta levels in Pacific/West Coast US States and trends in hypothyroidism among newborns after the Fukushima nuclear meltdown*
}

\author{
Joseph J. Mangano, Janette D. Sherman
}

Radiation and Public Health Project, New York, USA

Email: odiejoe@aol.com

Received 2 October 2012; revised 24 December 2012; accepted 29 January 2013

\begin{abstract}
Various reports indicate that the incidence of congenital hypothyroidism is increasing in developed nations, and that improved detection and more inclusive criteria for the disease do not explain this trend entirely. One risk factor documented in numerous studies is exposure to radioactive iodine found in nuclear weapons test fallout and nuclear reactor emissions. Large amounts of fallout disseminated worldwide from the meltdowns in four reactors at the Fukushima-Dai-ichi plant in Japan beginning March 11, 2011 included radioiodine isotopes. Just days after the meltdowns, I-131 concentrations in US precipitation was measured up to 211 times above normal. Highest levels of I-131 and airborne gross beta were documented in the five US States on the Pacific Ocean. The number of congenital hypothyroid cases in these five states from March 17-December 31, 2011 was $16 \%$ greater than for the same period in 2010, compared to a $3 \%$ decline in 36 other US States $(p<0.03)$. The greatest divergence in these two groups $(+28 \%)$ occurred in the period March 17-June 30 ( $p<0.04)$. Further analysis, in the US and in other nations, is needed to better understand any association between iodine exposure from Fukushima-Dai-ichi and congenital hypothyroidism risk.
\end{abstract}

Keywords: Congenital Hypothyroidism; Fukushima-Dai-Ichi; Iodine; Nuclear

\section{INTRODUCTION}

\subsection{Rise in Congenital Hypothyroidism Incidence Not Well Understood}

Since the development of a simple blood spot test through a neonatal heel prick in the 1960s [1], newborns

\footnotetext{
${ }^{*}$ There were no direct sponsors for this research, as the authors developed the manuscript independently. Mangano is an employee of the Radiation and Public Health Project.
}

in developed nations have been routinely screened for congenital hypothyroidism. $\mathrm{CH}$ is a disorder that results in stunted growth, lowered intelligence, deafness, and neurological abnormalities [2], but can be effectively treated if detected early. Increased incidence has been observed during the past two decades, including the United States, Australia, Italy, the United Kingdom, and Greece [3-7]. In the US, the rate increased $75.3 \%$ from 1987 to 2002 [3]. While changes in American laboratory practices and screening methods along with changes in proportions of multiple pregnancies, race, birth weight, and gender in the population may explain some of the increase, several reports conclude that there are other, unknown factors that account for this temporal trend [3,8-11].

Environmental factors pose one possible cause of these increases. One report examining the potential risk of $\mathrm{CH}$ from perchlorate in drinking water found no association [12]. Another found significant links between $\mathrm{CH}$ risk and levels of dioxin-like compounds and organochloride pesticides detected in the maternal breast milk [13].

\subsection{Exposure to Radioactive Iodine as a Factor in Congenital Hypothyroidism}

Another potential environmental risk factor is prenatal exposure to radioactive iodine isotopes, which seek out the susceptible fetal thyroid gland. For decades radioactive iodine has been recognized to cause adverse effects (including hypothyroidism) to the thyroid gland. The fetal thyroid, the first glandular structure to appear in the human embryo [14], begins to concentrate iodine and produce thyroid hormones by the $70^{\text {th }}$ day of gestation [15]. In the mid-1950s, during the period of atmospheric nuclear weapons tests, I-131 produced by fission was first detected in the adult human thyroid [16,17]. I-131 concentrations were calculated to be about 10 times higher in the human fetal thyroid vs. the human adult or hog thyroid [18], and maximum elevations in fetal thy- 
roids were detected approximately one month after nuclear explosions [19]. The main path of exposure to shortlived isotopes such as I-131 is via dairy products due to radioactive fallout deposition on forage [20].

One report on relatively low doses of I-131 exposures to rat embryos resulted in large decreases in fetal thyroxine and increases in Thyroid Stimulating Hormone (TSH), dependent upon the time of pregnancy that the exposure occurred [21]. A recent analysis discovered levels of whole blood iodine in three infants from Oregon (US) screened at birth exceeded the average for controls by a factor of 10 [22].

While anthropogenic radioactive iodine has existed following the discovery of fission in the 1940s, relatively few studies have examined the potential association between iodine exposure to the fetus and $\mathrm{CH}$ risk. The massive hydrogen bomb explosion "Bravo" on March 1, 1954 resulted in high doses to residents of the Marshall Islands and various thyroid disorders, including hypothyroidism in the child and adult. However, only two cases of $\mathrm{CH}$ were detected in the relatively small population $[23,24]$. In the five areas closest to the Chernobyl nuclear meltdown, the highest prevalence of hypothyroidism in children was observed in Gomel, the area with the highest exposures [25]. An examination of 160,000 local children exposed to Chernobyl fallout before age ten found a link with I-131 exposure and risk of juvenile hypothyroidism [26].

In Pennsylvania (US), the site of the March 1979 partial meltdown at the Three Mile Island nuclear power plant, the change in $\mathrm{CH}$ in nine month period before and after the event differed in upwind/western area (8 to 7 cases) and downwind/eastern areas (9 to 20 cases). [27, 28] The peak of I-131 from Chernobyl fallout in May 1986 in US milk was three times greater in northwest states than in southeast states; $1984-1985$ vs. $1986-1987$ changes in $\mathrm{CH}$ rates was $+23.3 \%$ in the northwest and $-1.0 \%$ in the southeast [29]. I-131 exposure due to releases from the Hanford (U.S.) nuclear weapons installation found a significantly elevated number of preterm births, which are linked to risk of $\mathrm{CH}$ [30]. The $\mathrm{CH}$ rate closest to the Savannah River (US) nuclear weapons plant was not found to be elevated [31].
More recently, $\mathrm{CH}$ rates of the four counties closest to the Indian Point, New York (US) nuclear plant, located mostly under 20 miles, are about twice that of the US, and especially high in the most recent period available [32]. The 1970-1993 total of airborne I-131 and particulates released by Indian Point was the $5^{\text {th }}$ greatest of 72 nuclear plants [33]. Data in Table 1 reflect official complications from state screening programs [34].

The meltdowns of four nuclear reactors at the Fukushima-Dai-ichi plant in Japan that began on March 11, 2011 after an earthquake and tsunami creates another basis to examine any potential effects of radioiodine exposure on $\mathrm{CH}$ rates. This report will review temporal $\mathrm{CH}$ trends in the US following the meltdowns, comparing those areas having elevated radioactivity with the rest of the US.

\section{METHODS}

\subsection{Measuring Exposures from Fukushima Meltdown}

The first of two major components needed to examine a potential association between Fukushima fallout and $\mathrm{CH}$ risk is exposure levels. Estimates of emissions from $\mathrm{Fu}-$ kushima are not precise; the reactors are not stable and are releasing radioactivity. Worldwide measurements show that 16,700 Peta-Becquerels of Xenon-133 were emitted by fall 2011, about 2.5 times more than that released by the 1986 Chernobyl meltdown. [35] Other reports place Fukushima emissions below Chernobyl's.

In the US, the plume arrived in the air above the west coast states on March 15, just four days after the start of the meltdowns [36]. US Environmental Protection Agency (EPA) measurements of I-131 in air, water, and milk were relatively few in number, and thus it is not possible to derive reliable geographic differences from these data. The most I-131 readings in the US environment were taken in precipitation, with 77 such measurements reported from March 22 to April 12, 2011. Detectable levels of I-131 in precipitation largely disappeared after this period; of the 10 measurements on April 14, five were "not detectable" and the others were just slightly above detectable levels of about 2.0 picocuries per liter [37].

Table 1. Congenital hypothyroid rates counties closest to Indian point nuclear site compared to US, 1997-2007.

\begin{tabular}{|c|c|c|c|c|c|c|}
\hline Area & Cases & Live Births & Cases/100,000 Live Births & $95 \% \mathrm{CI}$ & $\%$ vs. US & $P$ value \\
\hline *Four Counties, 1997-2004 & 135 & 185,099 & 72.93 & $90.6-85.2$ & +70.7 & $<0.0001$ \\
\hline *Four Counties, 2005-2007 & 73 & 68,019 & 107.32 & $82.7-131.9$ & +151.2 & $<0.0001$ \\
\hline${ }^{*}$ Total 1997-2007 & 208 & 253,118 & 82.18 & $90.6-85.2$ & +92.4 & $<0.0001$ \\
\hline
\end{tabular}

*Includes orange, putnam, rockland, and Westchester counties. 
Table 2 shows the distribution of the 77 measurements of I-131, covering 30 sites. After Fukushima, only 7 of 77 readings produced a "not detectable" result. But 18 of 77 measurements were $40 \mathrm{pCi} / 1$ or greater, at least 20 times above normal. The greatest concentrations were detected in Boise ID (242, 394, and 422), or 121 - 211 times above normal. Boise is in the northwest US, but the highest ten measurements included the East Coast cities of Jacksonville FL (148) and Boston MA (92). These data support the conclusion that I-131 from Fukushima entered the environment across the entire nation.

The Pacific Northwest National Laboratory documented that airborne levels of Xenon-133 in Washington State, on the Pacific coast, were 10,000 to 100,000 times greater than normal in the week following the disaster [38]. Xe-133 is a gas that travels more rapidly than other isotopes, but frequently is a tracer for future spatial patterns of other radionuclides. Moreover, Washington State was the site of radioactive "hot particles" soon after Fukudhima [39].

A team from California State University-Long Beach measured I-131 in kelp on the California coast on April 20, 2011 just over a month after the Fukushima meltdowns. The highest levels in the dry seaweed were found in Orange County in southern California (250 times greater than before the accident), Santa Cruz in northern California (200 times greater), and Los Angeles County (60 times greater) [40]. In New Hampshire, close to the Atlantic coast, during the period March-May 2011 I-131 doubled from prior periods [41].

A national study conducted by the National Geological Survey examined concentrations of wet depositions of fission-produced isotopes in soil at sites across the US, for several radioisotopes, between March 15 and April 5,

Table 2. Measurements of I-131 in US precipitation March 22 to April 12, 2011.

\begin{tabular}{cc}
\hline Concentration I-131 (pCi/l) & No. Measurements \\
\hline N.D. ${ }^{*}$ & 7 \\
$0.0-1.9$ & 1 \\
$2.0-9.9$ & 21 \\
$10.0-19.9$ & 18 \\
$20.0-39.9$ & 12 \\
$40.0-69.9$ & 6 \\
$70.0-99.9$ & 4 \\
$100.0-$ & 8 \\
TOTAL & 77 \\
\hline
\end{tabular}

*Not detectable, or probably around normal levels of 2.0.
2011. Results showed that for I-131, the highest depositions, in becquerels per cubic meter, occurred in northwest Oregon (5100), central California (1610), northern Colorado (833), coastal California (211), and western Washington (60.4). No other station recorded concentrations above 13. Similar results were observed for Cesium-134 and Cesium-137 [42]. All the cited locations are on or near the Pacific coast, with the exception of Colorado, in the western US.

Thus, the data indicate the greatest concentrations of environmental I-131 in the continental US after Fukushima occurred on the west coast. While the excess is difficult to quantify precisely, for purposes of this report comparisons in airborne gross beta concentrations will be made between the five Pacific and West Coast states (Alaska, California, Hawaii, Oregon, and Washington) and the remainder of the nation. The source of data is the US Environmental Protection Agency's twice-weekly measurements in nearly 100 US locations, creating a large sample of hundreds of measurements in the weeks after the arrival of Fukushima fallout.

\subsection{Collecting Data on Congenital Hypothyroidism Incidence}

The other principal component in this dose-response comparison involves $\mathrm{CH}$ incidence. Each of the $50 \mathrm{US}$ states maintains newborn screening program results, including $\mathrm{CH}$ cases. Because only annual data is made easily available on the internet, we conducted a telephone survey of states, requesting monthly numbers of CH cases, for each month in 2010 and 2011, according to the date of the baby's birth. Cases from births of March 1 - 16 and March 17 - 31 were separated to define the period after the arrival of Fukushima fallout in the US.

States were asked to provide only confirmed primary $\mathrm{CH}$ cases; these are newborns who test positive for the condition, and require therapeutic intervention to avoid adverse health effects. Transient $\mathrm{CH}$ cases are mostly newborns not confirmed to have $\mathrm{CH}$, and secondary $\mathrm{CH}$ cases are not recorded by all states. State programs were also asked to confirm that there was no change in $\mathrm{CH}$ definitions between 2010 and 2011 that would bias any temporal comparison. State definitions vary by thyroxine and TSH thresholds, so no valid intra-state comparisons can be made.

Calculating $\mathrm{CH}$ rates of cases per live births is not possible at this time, as final birth totals are not yet available. Official preliminary data indicate that there will be a 1 percent 2010-2011 decline in US births [43]; thus, comparing the number of $\mathrm{CH}$ cases for large populations should prove highly accurate as a predictor of the rate. In 2010, the five Pacific/West Coast States had a total population of $49,880,102$ ( $16.2 \%$ of the US total of 
$308,745,538)$ [44], and accounted for 693,676 (16.8\%) of the 4,130,665 US births in 2009 [45].

$\mathrm{CH}$ cases for births in the periods March 17 to December 31 (2010 and 2011) will be compared, for the Pacific/West Coast States and the remainder of the US Portions of this 290 day period will also be compared. Significance testing will be conducted using a t test, where $\mathrm{n}$ equals the number of Pacific/West Coast cases in 2010 and 2011, the observed change will be the change in the Pacific/West Coast, and the expected change will be the change for the remainder of the US.

\section{RESULTS}

\subsection{Largest US Radiation Increases after Fukushima in Pacific/West Coast States}

A review of US Environmental Protection Agency (EPA) data measuring airborne levels of gross beta was conducted, to compare 2010 and 2011 levels. The EPA uses air filters to measure aerosols at points close to ground level. The Agency typically does measurements about twice a week for 69 US sites. At the time of the analysis, data were only available up to October 4, 2011, and thus results for the periods January 1 to October 4 were compared for 2010 and 2011 [46]. Beta measurements include a variety of radioisotopes, of which I-131 is a portion, meaning gross beta as a proxy for relative exposures to the thyroid gland.

The largest amounts of radioactive fallout in the US environment from Fukushima occurred in late March and all of April 2011, before declining to levels typically recorded in 2010. Thus, 2010-2011 comparisons were made for two periods. The first was March 15-April 30, and the second was the remainder of the period (January 1March 14 plus May 1-October 4).

To identify an "exposed" population, we selected 18 EPA stations in the five Pacific/West Coast States for which at least 20 gross beta measurements were made during both 2010 and 2011. Many stations had considerably more, and thus a total of 1,043 and 1,083 measurements were used in the two years for the 18 stations.
We identified a "control" group representing the remainder of the US. Thus, 31 sites were selected, representing a wide geographic diversity. These sites recorded 59 to 79 airborne beta measurements each year for the 288-day period January 1-October 4, approximately twiceweekly measurements for the entire period. In all, 2,211 and 2,057 measurements were included in each respecttive year for the 31 sites. The list of these 18 exposed and 31 control sites is given in Appendix 1.

The "average" beta for each group was calculated by dividing the arithmetic mean by the number of sites (18 or 31). Table 3 presents the changes in average beta for exposed and control groups, for the periods of higher and lower/no exposure.

The data show that in the 18 sites in the Pacific/West Coast ("exposed") was 7.345 times higher in the March 15-April 30 period, compared to just 2.397 in the 31 other sites ("controls"), a ratio of 3.06. For the rest of the year, the 2010-2011 change was very small (0.983 and 1.018 , a ratio of 0.97 ), which is expected due to the absence of Fukushima fallout in both years.

Observations for some sites showed especially large increases. In the Pacific/West Coast, the largest changes were in the California cities of Eureka (increase of 38.264 times), Anaheim (14.941), and San Bernardino (12.054). In the 31 control sites, the only increases above 4.2 times were observed in Tucson AZ (9.320) and Salt Lake City UT (7.879), both located in the western US. The lowest figures were found in the southeastern cities of Baton Rouge LA (1.222) and Montgomery AL (1.212). This shows that for all areas of the US, 2010-2011 gross beta concentrations increased in the period March 15April 30. Thus, Fukushima fallout appeared to affect all areas of the US, and was especially large in some, mostly in the western part of the nation.

\subsection{Congenital Hypothyroidism Incidence Trends in US}

With the greatest airborne gross beta increases documented on the west coast, we can assess any changes in

Table 3. Change in average airborne gross beta concentration Pacific/West Coast sites (exposed) and other US sites (control) 2010-2011, periods of high and low/no fallout from Fukushima.

\begin{tabular}{|c|c|c|c|c|c|c|}
\hline & \multicolumn{2}{|l|}{2010 Average (n) } & \multicolumn{2}{|l|}{2011 Average (n) } & \multicolumn{2}{|c|}{ Change, 2010-2011 } \\
\hline Period & Exposed & Control & Exposed & Control & Exposed & Control \\
\hline \multicolumn{7}{|l|}{ High Fallout } \\
\hline March 15 - April 30 & $0.005112(190)$ & $0.008527(401)$ & $0.033016(225)$ & $0.020204(378)$ & 7.345 & 2.397 \\
\hline Jan. 1-March $14+$ May 1-Oct. 4 & $0.006027(853)$ & $0.009573(1810)$ & $0.005526(858)$ & $0.009670(1679)$ & 0.983 & 1.018 \\
\hline
\end{tabular}

Figures are in picocuries of gross beta per cubic meter of air. 
$\mathrm{CH}$ incidence. All US newborns diagnosed with primary CH born March 17-December 31, 2011 were exposed in utero to radioactive fallout from the Fukushima meltdowns. While these newborns were exposed at different phases of pregnancy, effects of exposure is elevated during the fetal period, compared to those during infancy, childhood, and adulthood.

Phone calls to state newborn screening program coordinators for monthly confirmed primary $\mathrm{CH}$ cases for 2010 and 2011 provided data for 41 of 50 states, representing $87 \%$ of all US births. Included in the 41 states were all five Pacific/West Coast States. Most of the other states not sharing statistical data were small states with under 10 cases per year, whose policies would not permit release of small numbers of cases due to confidentiality concerns. States reporting data are given in Appendix 2.

Table 4 presents the reported numbers of confirmed primary $\mathrm{CH}$ cases for the five (5) Pacific/West Coast States, along with cases for the other 36 US States.

The 2010-2011 ratio representing the change in $\mathrm{CH}$ cases was 1.16 for the five Pacific/West Coast States, rising from 281 to 327 confirmed cases. The 1.16 ratio exceeded the 0.97 ratio (decline in cases from 1208 to 1167 ) for the 36 control states; the difference is significant at $p<0.03$. Increases in ratios were observed in the exposed areas for the periods March 17-June 30 (1.28, significant at $\mathrm{p}<0.04)$ and July 1-December $31(1.10$, not significant at $\mathrm{p}<0.21$ ).

\section{DISCUSSION}

Congenital hypothyroidism $(\mathrm{CH})$ incidence is rising in various nations. Recent studies have examined patterns of these increases; better detection and more liberal definitions of $\mathrm{CH}$ may explain some of this pattern, but there is a general consensus that other factors are appearing to affect temporal trends. A well-documented risk factor affecting $\mathrm{CH}$ is exposure to the thyroid-seeking iodine isotopes such as I-131. Previous sources have linked elevated risk for hypothyroidism with nuclear weapons tests and nuclear power installations [22-34].

The meltdowns at the Fukushima-Daiichi nuclear plant in Japan beginning March 11, 2011 present an opportunity to examine a recent exposure to radiation, not just in Japan but in other nations that received the fallout. In the US, government officials measured concentrations of I-131 in precipitation up to 211 times above normal during the weeks following the meltdowns. There were increased concentrations of all beta-emitting radionuclides in the air during the six weeks following the beginning of Fukushima fallout. Compared to the same period a year earlier, the fallout increases were more than seven times greater in the five Pacific/West Coast States, compared to just over two times in the remainder of the US.

For births March 17 to December 31, the 2010-2011 change in confirmed $\mathrm{CH}$ cases in the five Pacific/West Coast States was significantly greater than for 36 other US States $(p<0.02)$. These 41 states represent $87 \%$ of US births, meaning that this result likely represents the pattern for the entire nation. The largest gap between the two groups of states occurred in the period March 17 to June 30, which represents fetuses exposed to environmental radioiodine during the third trimester of pregnancy, after the thyroid gland is more fully developed than in the first two trimesters.

Possible explanations for this finding should be considered. Prior research has shown that certain demographic groups are at greater risk for $\mathrm{CH}$, including female births, Hispanics, Asians, and births to older mothers. However, it is highly likely that distribution in gender, race/ethnicity, or maternal age changed little from 2010 to 2011. As mentioned, including all 50 states might have changed the comparison, but the sample of $87 \%$ of US births used in this report yields results very similar to the total. Knowing the number of live births and calculating $\mathrm{CH}$ rates could change the results, but the official estimate that live births will decline just 1 percent from 2010 to 2011 makes this unlikely to explain the difference between the two groups of states. The statistical significance of the findings $(p<0.03$ for March 17-December 31 births, and $p<0.04$ for March 17-June 30 births) make random yearly fluctuation unlikely as an explanation for the observed differences.

The potential for Fukushima fallout to contribute to rising $\mathrm{CH}$ in the Pacific/West Coast area of the US can only be explained if evidence of harm from relatively

Table 4. Confirmed primary congenital hypothyroid cases March 17-December 31 (2010 and 2011), 41 US States.

\begin{tabular}{|c|c|c|c|c|c|c|c|c|}
\hline & 5 Exposed States & & & $P$ value & 36 Control States & & & \\
\hline Period & 2010 & 2011 & Ratio & & 2010 & 2011 & Ratio & $P$ value \\
\hline March 17-December 31 & 281 & 327 & 1.16 & $<0.03$ & 1208 & 1167 & 0.97 & \\
\hline March 17-June 30 & 95 & 122 & 1.28 & $<0.04$ & 399 & 378 & 0.96 & \\
\hline July 1-December 30 & 186 & 205 & 1.10 & & 695 & 662 & 0.97 & \\
\hline
\end{tabular}

Note: For March 17-June 30 and July 1-December 31, the control state group excludes Indiana. 
low-dose radiation exposures is understood. Numerous reports have identified elevated disease risk from low radiation doses previously believed to be non-hazardous, or at least not able to be calculated using standard research methods. The first of these discoveries from the late 1950s showed prenatal abdominal X-rays nearly doubled the chance of the irradiated fetus dying before age ten $[47,48]$. US government officials estimated I-131 exposures from milk contaminated by Nevada above ground nuclear weapons tests in the period 1951 to 1958 [49], as the basis for the projection that as many as 212,000 Americans developed thyroid cancer from Nevada test fallout [50]. US officials also concluded (based on several dozen published studies) that occupational exposures received by workers in nuclear weapons plants caused a variety of cancers [51]. The consensus from results of these and other studies was that risks to health of radiation exposure follows a linear no-threshold model, even at the smallest doses [52]. Thus, while environmental levels of Fukushima fallout were thousands of times greater near the stricken plant than those in the US, these relatively low (but elevated) exposures should be analyzed for any potential links with diseases.

There are limitations to the data in this report that call for future actions to address them. One of these actions is to examine individual exposures to newborns with $\mathrm{CH}$, but the practical feasibility of calculating these data is very low. Another is to obtain more precise temporal and geographic data on environmental levels of specific radionuclides in the US after Fukushima, including I-131. Moreover, estimating specific exposures to humans as a consequence of the fallout would also be helpful in any future analyses of health risk. In addition, there are technical changes that may be made to data in this report, such as using a period greater than just 2010 as a baseline; including data on $\mathrm{CH}$ cases after 2011; and conversion of trends in cases to rates when official numbers of 2010-2011 live births by state and month become available. Review of $\mathrm{CH}$ changes in states with the highest exposures other than the Pacific/West Coast, which may include adjoining western states, can also be considered.

The data presented in this paper, including both exposure levels and $\mathrm{CH}$ incidence, should be considered as preliminary. They require confirmation and expansion, including long-term follow-up of infants and other children. However, the current findings should be noted, and encourage the conduct of future analyses of health effects from exposures to Fukushima fallout.

Congenital hypothyroidism can be used as one measure to assess any potential changes in U.S. fetal and infant health status after Fukushima because official data was available relatively promptly. However, health departments will soon have available for other 2010 and 2011 indicators of fetal/infant health, including fetal deaths, premature births, low weight births, neonatal deaths, infant deaths, and birth defects. While any adverse effects would first be expected to affect the susceptible fetus and infant, subsequent review of any changes in health status of older children and adults can be proceed.

Understanding why $\mathrm{CH}$ rates have risen in developed nations such as the US is a complex task, as multiple factors are likely involved. Exposure to radiation, especially the thyroid-seeking radioiodine isotopes, should be considered as one of these factors. The meltdown at Fukushima Dai-ichi presents an opportunity to analyze this factor, and studies such as this one should continue.

\section{REFERENCES}

[1] Guthrie, R. (1963) A simple phenylaline method for detecting phenylketonuria in large populations of newborn infants. Pediatrics, 32, 338-343.

[2] United States Public Health Service (1994) Newborn screening. American Family Physician, 50, 354-358.

[3] Harris, K.B. and Pass, K.A. (2007) Increase in congenital hypothyroidism in New York State and the United States. Molecular Genetics and Metabolism, 91, 268-277. doi:10.1016/j.ymgme.2007.03.012

[4] Kurinczuk, J.J., Bower, C., Lewis, B. and Byrne, G. (2007) Congenital hypothyroidism in Western Australia 19811998. Journal of Paediatric and Child Health, 38, 187191. doi:10.1046/j.1440-1754.2002.00812.x

[5] Corbetta, C., Weber, G., Cortinovis, F., Calebiro, D., Passoni, A., Vigone, M.C., Beck-Peccoz, P., Chiumello, G. and Persani, L. (2009) A 7-year experience with low blood TSH cutoff levels for neonatal screening reveals an unsuspected frequency of congenital hypothyroidism $(\mathrm{CH})$. Clinical Endocrinology, 71, 739-745.

[6] Pearce, M.S., Korada, M., Day, J., Turner, S., Allison, D., Kibirge, M. and Cheetham, T.D. (2010) Increasing incidence, but lack of seasonality, of elevated TSH levels, on newborn screening, in the North of England. Journal of Thyroid Research, 2010, Article ID: 101948. doi: $10.4061 / 2010 / 101948$

[7] Mengreli, C., Kanaka-Gantenbein, C., Girginoudis, P., Magiakou, M.A., Christakopoulou, I., Giannoulia-Karantana, A., Chrousos, G.P. and Dacou-Voutetakis, C. (2010) Screening for congenital hypothyroidism; the significance of threshold limit in false-negative results. Journal of Clinical Endocrinology and Metabolism, 95, 4283-4290. doi:10.1210/jc.2010-0057

[8] LaFranchi, S.H. (2011) Increasing incidence of congenital hypothyroidism: Some answers, more questions. Journal of Clinical Endocrinology and Metabolism, 96, 23952397. doi:10.1210/jc.2011-1850

[9] Hertzberg, V., Mei, J. and Therrell, B.L. (2010) Effect of laboratory practices on the incidence rate of congenital hypothyroidism. Pediatrics, 125, 548-553. doi:10.1542/peds.2009-1975E

[10] Waller, D.K., Anderson, J.L., Lorey, F. and Cunningham, 
G.C. (2000) Risk factors for congenital hypothyroidism: An investigation of infant's birth weight, ethnicity, and gender in California, 1990-1998. Teratology, 62, 36-41. doi:10.1002/1096-9926(200007)62:1<36::AID-TERA8> 3.0.CO;2-W

[11] Oliveri, A., Medda, E., DeAngelis, S., Valensise, H., DeFelice, M., Fazzini, C., Cascino, I., Cordeddu, V., Sorcini, M. and Stazi, M.A. (2007) High risk of congenital hypothyroidism in multiple pregnancies. Journal of Clinical Endocrinology and Metabolism, 92, 3141-3147. doi:10.1210/jc.2007-0238

[12] Buffler, P.A., Kelsh, M.A., Lau, E.C., Edinboro, C.H., Barnard, J.C., Rutherford, G.W., Daaboul, J.J., Palmer, L. and Lorey, F.W. (2006) Thyroid function and perchlorate in drinking water: An evaluation among California newborns, 1998. Environmental Health Perspectives, 114, 798804. doi:10.1289/ehp.8176

[13] Nagayama, J., Kohno, H., Nunisue, T., Kataoka, K., Shimomura, H., Tanabe, S. and Konishi, S. (2007) Concentratins of organichlorine pollutants in mothers who gave birth to neonates with congenital hypothyroidism. Chemosphere, 68, 972-976. doi:10.1016/j.chemosphere.2007.01.010

[14] Arey, L.B. (1954) Developmental anatomy. W.B. Saunders, Philadelphia.

[15] Howdeshell, K. (2002) A model of the development of the brain as a construct of the thyroid system. Environmental Health Perspectives, 110, 337-348. doi:10.1289/ehp.02110s3337

[16] Van Middlesworth, L. (1956) Radioactivity in thyroid glands following nuclear weapons tests. Science, 123, 982983. doi: $10.1126 /$ science. 123.3205 .982

[17] Comar, C.L., Trum, B.F., Kuhn, U.S., Wasserman, R.H., Nold, M.M. and Schooley, J.C. (1957) Thyroid radioactivity after nuclear weapons tests. Science, 126, 16-18. doi:10.1126/science.126.3262.16

[18] Beierwaltes, W.H., Cranae, H.R., Wegst, A., Spafford, N.R. and Carr, E.A. (1960) Radioactive iodine concentration in the fetal human thyroid gland from fall-out. The Journal of the Aerican Medical Association, 173, 18951902. doi:10.1001/jama.1960.03020350013003

[19] Beierwaltes, W.H., Hilger, M.T. and Wegst, A. (1963) Radioactive concentrations in fetal human thyroid from fallout. Health Physics, 9, 1263-1266. doi:10.1097/00004032-196312000-00030

[20] Gardner, R.J. (1960) An assessment of the quantities of fission products likely to be found in milk in the event of serial contamination of agricultural land. Nature, 186, 1063-1064. doi:10.1038/1861063a0

[21] Usenko, V., Lepekhin, E., Lyzogubov, V., Kornilovska, I., Ushakova, G. and Witt, M. (1999) The influence of low doses 131I-induced maternal hypothyroidism on the development of rat embryos. Experimental Toxicology and Pathology, 51, 223-227. doi:10.1016/S0940-2993(99)80100-6

[22] Connelly, K.J., Boston, B.A., Pearce, E.N., Sesser, D., Snyder, D., Braverman, L.E., Pino, S. and Lafranchi, S.H. (2012) Congeneital hypothyroidism caused by excess prenatal maternal iodine ingestion. Journal of Pediatrics,
161, 760-762. doi:10.1016/j.jpeds.2012.05.057

[23] Cronkite, E.P., Conard, R.A. and Bond, V.P. (1997) Historical events associated with fallout from bravo shotOperation castle and $25 \mathrm{Y}$ of medical findings. Health Physics, 73, 176-186. doi:10.1097/00004032-199707000-00014

[24] Cronkite, E.P., Bond, V.P. and Conard, R.A (1995) Medical effects of exposure of human beings to fallout radiation from a thermonuclear explosion. Stem Cells, 13, 49-57.

[25] Williams, D. (1996) Chernobyl and hypothyroidism. Lancet, 348, 476. doi:10.1016/S0140-6736(05)64570-9

[26] Goldsmith, J.R., Grossman, C.M., Morton, W.E., Nussbaum, R.H., Kordysh, E.A., Quastel, M.R., Sobel, R.B. and Nussbaum, F.D. (1999) Juvenile hypothyroidism among two populations exposed to radioiodine. Environmental Health Perspectives, 107, 303-308. doi:10.1289/ehp.99107303

[27] MacLeod, G. (1982) A role for public health in the nuclear age. American Journal of Public Health, 72, 237239. doi:10.2105/AJPH.72.3.237

[28] MacLeod, G.K. (1981) Some public health lessons from three mile island: A case study in chaos. Ambio, 1, 18-23.

[29] Mangano, J.J. (1996) Chernobyl and hypothyroidism. Lancet, 347, 1482-1483. doi:10.1016/S0140-6736(96)91716-X

[30] Tatham, L.M., Bove, F.J., Kaye, W.E. and Spengler, R.F. (2002) Population exposures to I-131 releases from Hanford Nuclear Reservation and preterm birth, infant mortality, and fetal deaths. International Journal of Hygiene and Environmental Health, 205, 41-48. doi:10.1078/1438-4639-00128

[31] Halfrick, D.L., Grinzaid, K.A., Brown, A.L. and Fernhoff, P.M. (1999) Monitoring the prevalence of congenital hypothyroidism for 20 years near the Savannah River site. Journal of the Medical Association of Georgia, 88, 38-40.

[32] Mangano, J.J. (2009) Newborn hypothyroidism near the indian point nuclear plant. www.radiation.org/reading/pubs/091125/hypothyroid ind ianpoint.pdf

[33] Tichler, J., Doty, K. and Lucadamo, K. Radioactive materials released from nuclear power plants, annual reports, 1970-1993 annual reports. NUREG/CR-2907. Brookhaven National Laboratory, Upton.

[34] National newborn screening and genetics resource center. http://genes-r-us.uthscsa.edu/newborn reports

[35] (2011) Reactor accident Fukushima-New international study on emissions of radioactive substances into the atmosphere.

http://www.zamg.at/docs/aktuell/20111021 fukushima_r eview.pdf

[36] Meteo France (2011) Accident de la centrale de Fukushima Daiichi: Modelisation de la dispersion des rejets radioactifs dans l'atmosphere a l'echele mondiale-Version du 22 mars 2011.

http://irsn.fr.FR/popup/Pages/irsn-meteo-france 22mars.a $\underline{\operatorname{spx}}$

[37] US Environmental Protection Agency, Office of Radia- 
tion Protection. http://iaspub.epa.gov/enviro/erams query.v2.simple

[38] Bowyer, T.W., Biegalski S.R., Cooper, M., Eslinger, P.W., Haas, D., Hayes, J.C., Miley, H.S., Strom, D.J. and Woods, V. (2011) Elevated radioxenon detected remotely following the Fukushima nuclear accident. Journal of Environmental Radioactivity, 102, 681-687. doi:10.1016/j.jenvrad.2011.04.009

[39] Hernandex-Ceballos, M.A., Hong, G.H., Lozano, R.L., Kim, Y.I., Lee, H.M., Yeh, S-W. and Bolivar, J.P. (2012) Tracking the complete revolution of surface westerlies over the Northern Hemisphere using radionuclides emitted from Fukushima. The Science of the Total Environment, 438, 80-85. doi:10.1016/j.scitotenv.2012.08.024

[40] Manley, S.L. and Lowe C.G. (2012) Canopy-formiing kelps as California's coastal dosimeter: 131-I from damaged Japanese reactor measured in Macrocystis pyrifera. Environmental Science \& Technology, 46, 3731-3736. doi:10.1021/es203598r

[41] Landis, J.D., Hamm, N.T., Renshaw, C.E., Dade, W.B., Magilligan, F.J. and Gartner, J.D. (2012) Surficial redistribution of fallout 131-Iodine in a small temperate catchment. Proceedings of the National Academy of Sciences, 13 March 2012, 4064-4069.

[42] Weatherbee, G.A., Gay, D.A., Debey, T.M., Lehmann, C.M. and Nillas, M.A. (2012) Wet deposition of fissionproduct isotopes to North America from the Fukushima Dai-ichi Incident, March 2011. Environmental Science and Technology, 46, 2574-2582. doi:10.1021/es203217u

[43] Hamilton, B.E. and Sutton, P.D. (2011) Recent trends in births and fertility rates through December 2011. http://www.cdc.gov/nchs/data/hestat/births fertility dece mber 2011/births fertility december 2011.html

[44] US Census Bureau. 2010 census of the US population. http://quickfacts.census.gov/qfd/index.html

[45] US Centers for Disease Control and Prevention. Natality. http://wonder.cdc.gov/natality.html

[46] US Environmental Protection Agency. Envirofacts. http://www.epa.gov/envivro/facts/radnet/customized.html

[47] Stewart, A., Webb, J., Giles, D. and Hewitt, D. (1956) Malignant disease in childhood and diagnostic irradiation in utero. Lancet, 2, 447. doi:10.1016/S0140-6736(56)91923-7

[48] Stewart, A., Webb, J. and Hewitt, D. (1958) A survey of childhood malignancies. British Medical Journal, 1, $1495-$ 1508. doi:10.1136/bmj.1.5086.1495

[49] US Department of Health and Human Services (1997) Estimated exposure and thyroid doses following Nevada atmospheric nuclear bomb tests. NIH Pub. No. 97-4264, National Cancer Institute, Bethesda.

[50] National Research Council, Committee on Thyroid Screening (1999) Exposure of the American people to iodine131 from the Nevada bomb tests. National Academy Press, Washington DC.

[51] Alvarez, R. (2000) The risks of making nuclear weapons: A review of the health and mortality experience of US department of energy workers. The Government Accountability Project, Washington DC.

[52] National Research Council (2005) Committee on the biological effects of ionizing Radiation. Health effects of exposure to low levels of ionizing radiation: BEIR VII. National Academy Press, Washington DC. 


\section{Appendix 1}

US environmental protection agency sites used in calculation of gross beta concentration in air (Table 2) for January 1-October 4, 2010 and 2011.

\begin{tabular}{ccc}
\hline 18 Pacific/West Coast Sites & 31 Other US Sites & \\
\hline ("Exposed” Population) & ("Control” Population) & Lexington KY \\
\hline Anaheim CA & Albany NY & Little Rock AR \\
Anchorage AK & Baton Rouge LA & Lynchburg VA \\
Bakersfield CA & Bay City MI & Montgomery AL \\
Eureka CA & Charlotte NC & Oak Ridge TN \\
Fresno CA & Cincinnati OH & Pierre SD \\
Hilo HI & Cleveland OH & Richmond VA \\
Honolulu HI & Dallas TX & Salt Lake City UT \\
Los Angeles CA & Denver CO & San Angelo TX \\
Olympia WA & Des Moines IA & Springfield MO \\
Portland OR & Detroit MI & Trenton NJ \\
Richmond CA & Edison NJ & Topeka KS \\
Riverside CA & Indianapolis IN & Tucson AZ \\
Sacramento CA & Jackson MS & Washington DC \\
San Bernardino CA & Jefferson City MO & Worcester MA \\
San Diego CA & Kansas City KS & \\
San Francisco CA & Lexington KY & \\
San Jose CA & & \\
Spokane WA & &
\end{tabular}

\section{Appendix 2}

US States providing cases of primary congenital hypothyroid cases used in calculation of 2010-2011 changes (Table 3).

\begin{tabular}{ccc}
\hline 5 Pacific/West Coast States & 36 Other US States & \\
\hline ("Exposed" Areas) & (“Control” Areas) & Missouri \\
Alaska & Alabama & Montana \\
California & Arizona & Nebraska \\
Hawaii & Arkansas & New Jersey \\
Oregon & Colorado & New Mexico \\
Washington & Florida & North Carolina \\
& Georgia & North Dakota \\
10 States Not Included & Idaho & Ohio \\
Connecticut & Illinois & Oklahoma \\
Delaware & Indiana & Pennsylvania \\
District of Columbia & Kansas & Rhode Island \\
Iowa & Kentucky & South Carolina \\
Massachusetts & Louisiana & Tennessee \\
New Hampshire & Maine & Texas \\
New York & Maryland & Vermont \\
Utah & Michigan & Virginia
\end{tabular}

